\title{
p38 MAPK-MK2 pathway regulates the heat-stress-induced accumulation of reactive oxygen species that mediates apoptotic cell death in glial cells
}

\author{
HONGBO LI ${ }^{1,2^{*}}$, YANAN LIU ${ }^{3 *}$, ZHENGTAO GU ${ }^{4}, \mathrm{LI} \mathrm{LI}^{4}, \mathrm{YUNSONG} \mathrm{LIU}^{5}, \mathrm{LIN} \mathrm{WANG}^{6}$ and LEI SU ${ }^{1,5}$ \\ ${ }^{1}$ Graduate School Department, Southern Medical University, Guangzhou, Guangdong 510515; ${ }^{2}$ Department of Intensive \\ Care Unit, The First Affiliated Hospital of Guangzhou University of Chinese Medicine, Guangzhou, Guangdong 510405; \\ ${ }^{3}$ Department of Intensive Care Unit, Nanfang Hospital, Southern Medical University, Guangzhou, Guangdong 510515; \\ ${ }^{4}$ Intensive Care Unit, The Third Affiliated Hospital of Southern Medical University, Guangzhou, Guangdong 510630; \\ ${ }^{5}$ Intensive Care Unit, General Hospital of Guangzhou Military Command, Key Laboratory of Tropical Zone Trauma \\ Care and Tissue Repair of PLA, Guangzhou, Guangdong 510010; ${ }^{6}$ Emergency Department, The First Affiliated \\ Hospital of Guangzhou University of Chinese Medicine, Guangzhou, Guangdong 510405, P.R. China
}

Received May 28, 2016; Accepted August 15, 2017

DOI: $10.3892 / 01.2017 .7360$

\begin{abstract}
Previous studies have demonstratedf that heat stress can induce injury of the central nervous system and lead to neuronal cell apoptosis. However, the molecular mechanisms underlying these cellular changes remain unclear. In the present study, flow cytometry was used to investigate heat-stress-induced apoptosis, and caspase- 3 activation was also assessed in neurons. The role of reactive oxygen species (ROS) accumulation in the heat-stress-induced apoptosis of neurons was demonstrated using the antioxidant drug manganese (III) tetrakis (4-benzoic acid)porphyrin. The present study presents evidence that heat stress induces mitogen-activated protein kinase (MAPK) activation in rat malignant glioma F98 cells. Following the inhibition of different MAPKs with a range of specific inhibitors, SB203580 (an inhibitor of p38 MAPK), but not PD98059 (an inhibitor of extracellular signal-regulated kinases) or SP600125 (an inhibitor of c-Jun $\mathrm{N}$-terminal kinases), diminished the production of ROS and
\end{abstract}

Correspondence to: Professor Lei Su, Intensive Care Unit, General Hospital of Guangzhou Military Command, Key Laboratory of Tropical Zone Trauma Care and Tissue Repair of PLA, 111 Liuhua Road, Guangzhou, Guangdong 510010, P.R. China

E-mail: slei_ICU@163.com

Dr Lin Wang, Emergency Department, The First Affiliated Hospital of Guangzhou University of Chinese Medicine, 16 Airport Road, Guangzhou, Guangdong 510405, P.R. China

E-mail: 59338765@qq.com

*Contributed equally

Key words: heat stress, apoptosis, reactive oxygen species, mitogen-activated protein kinase, mitogen-activated protein kinaseactivated protein kinase 2 , glial cells apoptosis, and prevented activation of the p38-downstream kinase MAPK-activated protein kinase 2 (MK2) in neurons. Inhibiting MK2 with dominant negative adenoviral constructs or a specific inhibitor significantly decreased normal and heat-stress-induced ROS accumulation and cell apoptosis, whereas inhibition of another kinase downstream of p38 MAPK, MAPK-activated protein kinase 5, by transfection with another adenoviral construct did not exert the same effects. Taken together, these findings indicate that heat stress stimulation induces p38-MK2 pathway activation, which exerts a pro-apoptotic effect by regulating ROS accumulation in neurons.

\section{Introduction}

Acute heat stroke causes thermal injury of cells and changes to the circulatory system, which can in turn trigger extensive tissue injury to the blood coagulation system, the liver, heart and kidneys, and, most importantly, to the central nervous system (CNS) (1). According to the report of a cohort study covering 16 emergency departments, only $57 \%$ patients survived following heat stroke during the August 2003 heat wave in Paris (2); even following discharge from the hospital, survivors continued to suffer neurological damage during the 1995 heat wave in Chicago (3). The mortality rate may increase as a result of global warming and the expected universal increase in the intensity and frequency of heat waves $(4,5)$.

Combining prior studies, a previous review reported that high temperatures can cause certain CNS malformations, and that heat induces programmed cell death, which causes teratogenic damage to the developing brain (6). However, the mediation between metabolic changes and cell apoptosis remains poorly characterized.

Mitogen-activated protein kinase (MAPK) signaling pathways are involved in heat-stress-induced organ injury and human umbilical vein endothelial cell (HUVEC) apoptosis $(7,8)$. Activation of MAPK signaling pathways in 
responding to stressors, such as oxidative stress, also induces neuronal apoptosis through the mitochondria-dependent pathway (9). The representative mammalian MAPK pathways, which include p38 MAPK, c-Jun N-terminal kinase (JNK), and extracellular signal-regulated kinase 1/2 (ERK1/2), are concatenated via three consecutive phosphorylation events, which are mediated by a MAPK, a MAPK kinase, and a MAPK kinase kinase (10-12). Substrates with distinct functions are phosphorylated by MAPKs, including other protein kinases that are recognized as MAPK-activated protein kinases (MAPKAPKs; also known as MKs) (13). MK5 and MK2 exhibit considerable structural, functional and evolutional similarities, and are substrates for p38 $(14,15)$. The function of the p38 stress-activated protein kinase/MK2 axis in apoptosis and inflammation has been recorded in detail (16), but whether MK2 and MK5 participate in heat-stress-induced neuron cell apoptosis remains unclear.

Reactive oxygen species (ROS) are involved in cell apoptosis in response to thermal injury (17). The overproduction of ROS may cause necrosis or apoptosis in various pathological conditions, including ischemia (18). To assess the roles of MK5 and MK2 in cell apoptosis mediated by heat-stress-induced ROS accumulation, the present study utilized the application of adenoviral dominant-negative and -positive constructs of MK2 and MK5 into F98 cells. Dominant-negative MK2 [Ad-MK2(A)], or a specific inhibitor of MK2, impeded heat stress-induced ROS production and cell apoptosis, while Ad-MK5(A) did not. These findings indicate that p38 MAPK-MK2 plays a part in suppressing apoptosis following heat stress. Hence, p38 MAPK-MK2 signaling could be a treatment target for use in improving the outcomes of heatstroke patients.

\section{Materials and methods}

Cell culture and treatments. Rat malignant glioma F98 cells were procured from the Type Culture Collection of the Chinese Academy of Sciences (Shanghai, China). F98 cells were incubated in Dulbecco's modified Eagle's medium containing $100 \mathrm{U} / \mathrm{ml}$ of penicillin, $100 \mu \mathrm{g} / \mathrm{ml}$ of streptomycin (Invitrogen; Thermo Fisher Scientific, Inc., Waltham, MA, USA) and 10\% (v/v) fetal bovine serum (Invitrogen; Thermo Fisher Scientific, Inc.). The temperature was controlled at $37^{\circ} \mathrm{C}$ and the atmosphere was humidified, comprising $95 \%$ air and $5 \% \mathrm{CO}_{2}$. Culture dishes were incubated in a circulating water bath for $60 \mathrm{~min}$ at $43 \pm 0.5^{\circ} \mathrm{C}$ for heat stress, or at $37 \pm 0.5^{\circ} \mathrm{C}$ for control. Cells were further cultured at $37^{\circ} \mathrm{C}$ for the designated time following the replacement of culture media with fresh media.

Infection with adenoviral constructs. Generation of recombinant adenoviral constructs was performed as previously described (19,20). Briefly, the present study used Ad-MKK6(E), Ad-MK2(E), Ad-MK5(E), the constitutively active forms of MKK6, MK2 and MK5 encoded by recombinant adenovirus. The present study also used Ad-MKK6(A), Ad-MK2(A) and Ad-MK5(A), the constitutively negative forms of MKK6, MK2 and MK5. These adenoviruses were constructed by Vigene Biosciences (Jinan, China). F98 cells were seeded in $35-\mathrm{mm}$ Petri dishes $\left(1 \times 10^{5} / \mathrm{dish}\right), 72 \mathrm{~h}$ prior to infection $\left[10^{3}\right.$ inclusion-forming units (IFU)/cell], and were exposed to heat stress after a 24-h incubation period.
Flow cytometric analysis of cell apoptosis using Annexin Vfluorescein isothiocyanate (FITC)/PI staining. The proportions of apoptotic cells in each group were analyzed by flow cytometry using an Annexin V-FITC apoptosis kit (Shanghai Lianke Biology Co., Ltd., Shanghai, China), according to the manufacturer's protocol. Approximately $1 \times 10^{6}$ cells were collected, and were washed with ice-cold PBS prior to resuspension in binding buffer containing $5 \mu \mathrm{l}$ FITC-Annexin V and $10 \mu \mathrm{l}$ propidium iodide. All samples were analyzed using a flow cytometer (FACSCanto ${ }^{\mathrm{TM}}$ II; BD Biosciences, San Jose, CA, USA) and analyzed using FlowJo software version 9.0 (Tree Star, Inc., Ashland, OR, USA).

Assay for caspase-3 activity. Caspase-3 activity was determined using a caspase-3 activity assay kit, according to the manufacturer's protocol (Biovision, Inc., Milpitas, CA, USA). Briefly, the cells were lysed in caspase-3 sample lysis buffer (Biovision, Inc.). The homogenates were then centrifuged at $10,000 \mathrm{x} \mathrm{g}$ at $4^{\circ} \mathrm{C}$ for $10 \mathrm{~min}$ and the supernatant was collected for protein estimation using bicinchoninic acid for the caspase-3 assay. The cell lysates were then exposed to the DEVD substrate conjugate provided in the kit for $1 \mathrm{~h}$ at $37^{\circ} \mathrm{C}$. The sample was measured using an automatic microplate reader (SpectraMax M5; Molecular Devices, LLC, Sunnyvale, CA, USA) at an excitation of $400 \mathrm{~nm}$ and emission of $505 \mathrm{~nm}$.

Measurements of ROS. ROS levels were assessed using 2',7'-dichlorodihydrofluorescein diacetate (DCFH-DA; Molecular Probes; Thermo Fisher Scientific, Inc.), which is converted to highly fluorescent 2 ',7'-dichlorofluorescein (DCF) in the presence of ROS. F98 cells $\left(3 \times 10^{5}\right)$ were incubated at $43^{\circ} \mathrm{C}$ for $1 \mathrm{~h}$ before incubation at $37^{\circ} \mathrm{C}$ for $0,3,6$ or $12 \mathrm{~h}$; cells were then incubated with $5 \mathrm{mM} \mathrm{DCF}-D A$ at $37^{\circ} \mathrm{C}$ for $30 \mathrm{~min}$ in darkness. $\mathrm{H}_{2} \mathrm{O}_{2}$ was used as a positive control; $\mathrm{H}_{2} \mathrm{O}_{2}$ $(200 \mu \mathrm{M})$ was added to $\mathrm{F} 98$ cells and incubated at $37^{\circ} \mathrm{C}$ for $1 \mathrm{~h}$. In addition, cells were pretreated with or without MnTBAP for $1 \mathrm{~h}$ at $37^{\circ} \mathrm{C}$ and were then incubated at $43^{\circ} \mathrm{C}$ (HS) or $37^{\circ} \mathrm{C}$ (control) for $60 \mathrm{~min}$. Analysis of the fluorescence intensity of DCF was subsequently performed using a flow cytometer, and images were obtained via laser scanning confocal microscopy (OLS4100; magnification, x40; Olympus Corporation, Tokyo, Japan) at an excitation of $488 \mathrm{~nm}$ and emission of $530 \mathrm{~nm}$.

Western blot analysis. F98 cells $\left(\sim 1 \times 10^{6}\right)$ were maintained at $37^{\circ} \mathrm{C}$ (control) or $43^{\circ} \mathrm{C}$ (HS) for $60 \mathrm{~min}$ and further incubated for $0,3,6$ or $12 \mathrm{~h}$ at $37^{\circ} \mathrm{C}$. Cells were pretreated with CMPD-1 (10 $\mu \mathrm{M}$; cat. no. 263847-55-8; Tocris Bioscience, Bristol, UK), MnTBAP (10 $\mu \mathrm{M}$; cat. no. ab141496; Abcam, Cambridge, MA, USA), SP600125 (10 $\mu$ M; cat. no. ab120065; Abcam), SB203580 (5 $\mu \mathrm{M}$; cat. no. ab120162; Abcam), PD98059 (10 $\mu \mathrm{M}$; cat. no. ab120234; Abcam), SB202474 (10 $\mu$ M; cat. no. IMA1013; Jingke Science and Technology Co., Ltd., Shanghai, China), the specific inhibitors of MK2, ROS, JNK, p38, ERK and the negative control, respectively, at $37^{\circ} \mathrm{C}$ for $30 \mathrm{~min}$. Cells were then exposed to heat stress or control heat treatment, followed by recovery at $37^{\circ} \mathrm{C}$ for $12 \mathrm{~h}$. Control cells were treated with PBS instead of LPS and were constantly incubated at $37^{\circ} \mathrm{C}$. Cells were homogenized in radioimmunoprecipitation assay lysis buffer with phenylmethylsulfonyl fluoride (Sigma-Aldrich; Merck KGaA, Darmstadt, Germany). Following centrifugation 
at $14,000 \mathrm{x} \mathrm{g}$ at $4^{\circ} \mathrm{C}$ for $10 \mathrm{~min}$, the supernatants were used for western blot analysis. Protein concentration was determined using a Bicinchoninic Acid Protein Assay kit (Thermo Fisher Scientific, Inc.). Proteins (20 $\mu \mathrm{g} /$ well) were separated by SDS-PAGE using 10\% SDS polyacrylamide gels and transferred onto polyvinylidene difluoride membranes. Membranes were blocked with blocking solution (5\% skimmed milk diluted with PBS) at room temperature for $2 \mathrm{~h}$, followed by incubation with primary antibodies. The following rabbit primary antibodies were used at a 1:2,000 dilution: GAPDH (cat. no. ab70699; Abcam), phosphorylated (p)-JNK (cat. no. 4668; Cell Signaling Technology, Inc., Danvers, MA, USA), p-p38 (cat. no. 4511; Cell Signaling Technology, Inc.), p-ERK1/2 (cat. no. 4370; Cell Signaling Technology, Inc.), JNK (cat. no. 9252; Cell Signaling Technology, Inc.), p38 (cat. no. 8690; Cell Signaling Technology, Inc.), ERK1/2 (cat. no. 4695; Cell Signaling Technology, Inc.), MK2 (cat. no. ab131531; Abcam), p-MK2 (cat. no. ab63378; Abcam), MK5 (cat. no. 7419; Cell Signaling Technology, Inc.), p-MK5 (cat. no. 9771; Cell Signaling Technology, Inc.), caspase-3 (cat. no. 14220S; Cell Signaling Technology, Inc.) and cleaved caspase-3 (cat. no. 9654S; Cell Signaling Technology, Inc.) overnight at $4^{\circ} \mathrm{C}$. A horseradish peroxidase-conjugated goat anti-rabbit IgG antibody functioned as the secondary antibody (1:5,000; cat. no. 7074; Cell Signaling Technology, Inc.) for incubation at room temperature for $2 \mathrm{~h}$. Proteins were visualized using an Enhanced Chemiluminescence Reagent (Pierce; Thermo Fisher Scientific, Inc.). Membranes were exposed to light-sensitive film and quantified using Image $\mathrm{J}$ software version 1.3.4.67 (National Institutes of Health, Bethesda, MD, USA).

Statistical analysis. SPSS 13.0 software (SPSS, Inc., Chicago, IL, USA) was used to analyze all data for statistical significance. Data are expressed as the mean \pm standard error from no less than three independent duplicate experiments. One-way analysis of variance was performed followed by Fisher's least significant difference post hoc test for multiple comparisons. $\mathrm{P}<0.05$ was considered to indicate a statistically significant difference.

\section{Results}

Heat stress increases cell apoptosis in F98 cells. To assess whether heat stress could induce F98 cells to apoptose in a heat-stress cell model, the proportion of apoptotic cells were quantitatively evaluated using flow cytometry. After F98 cells were subjected to heat stress at $43^{\circ} \mathrm{C}$ for $60 \mathrm{~min}$, the quantity of early apoptotic cells increased markedly over time, with early apoptosis induced in $28.97 \pm 1.855$ of cells by $12 \mathrm{~h}$, which was significantly higher compared with that in the control treatment group 4.178 \pm 0.5901 ( $\mathrm{P}<0.05$; Fig. 1A). Caspase-3 activity was observed using the fluorogenic substrate Ac-DEVD-AMC at $0,3,6$ and $12 \mathrm{~h}$ following $60 \mathrm{~min}$ of $43^{\circ} \mathrm{C}$ heat stress (Fig. 1B). The activity of caspase- 3 mirrored the occurrence of cell apoptosis.

Heat stress increases ROS generation in F98 cells. On the basis of evidence that ROS generation plays a crucial part in the heat-stress response, whether accumulation of ROS in F98 cells could be influenced by heat stress was investigated.
A
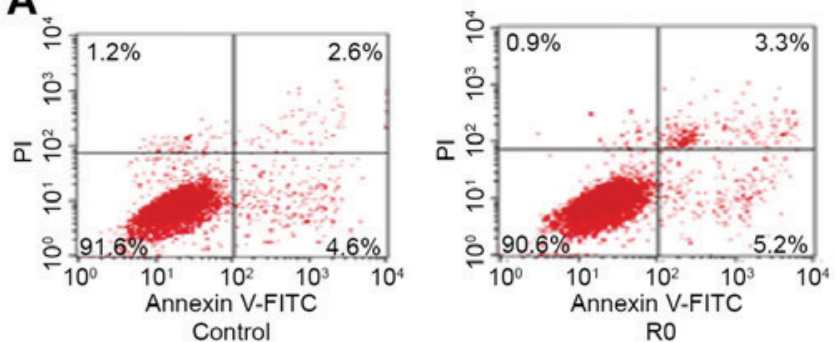

RO

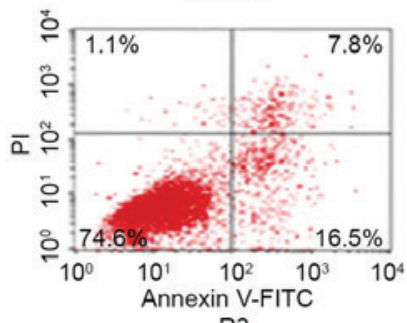

R3
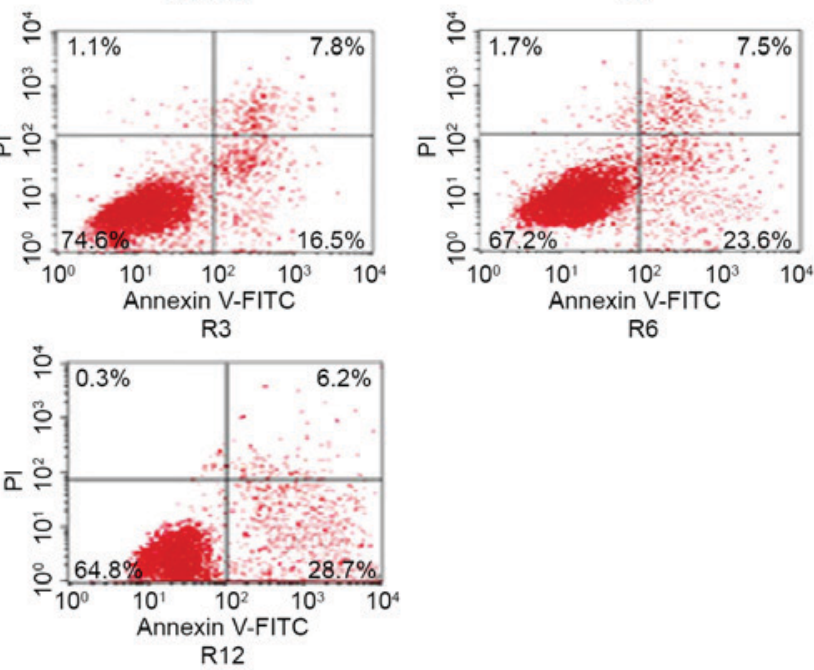

R6

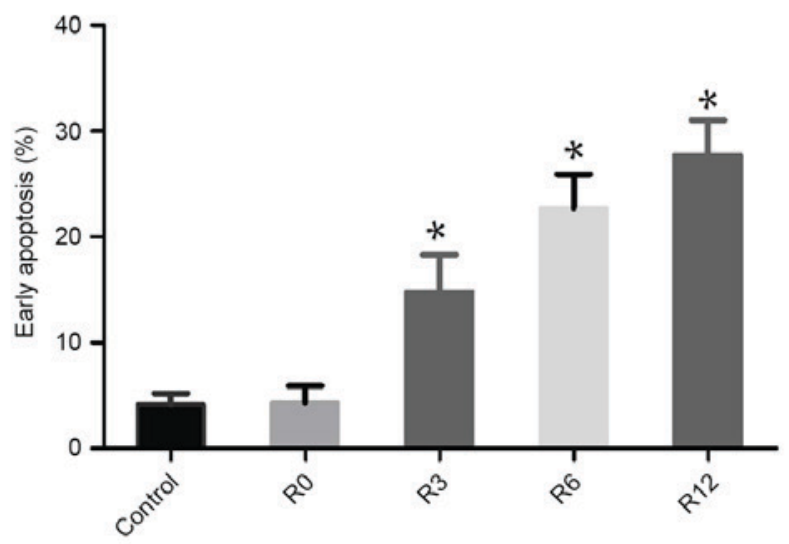

B

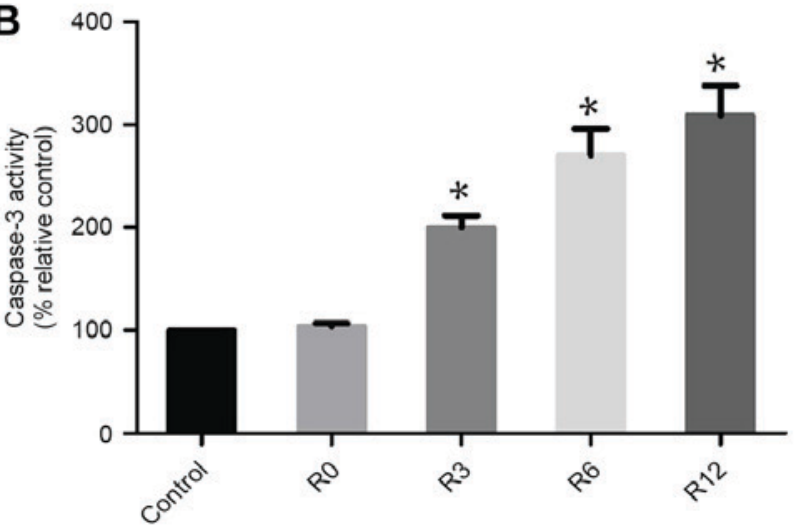

Figure 1. Heat stress induced apoptosis and caspase-3 activation. F98 cells were incubated at $43^{\circ} \mathrm{C}$ for $60 \mathrm{~min}$ to simulate heat stress. Culture medium was then replaced prior to further incubation of the cells for $0,3,6$ or $12 \mathrm{~h}$ (R0 to R12, respectively). (A) Analysis of apoptosis was performed with flow cytometry using Annexin V-FITC/PI staining. (B) The fluorogenic substrate Ac-DEVD-AMC was applied to measure enzymatic activity of caspase-3, which was expressed relative to the control cells incubated at $37^{\circ} \mathrm{C}$ (set as $100 \%)$. ${ }^{*} \mathrm{P}<0.05$ vs. control groups $\left(37^{\circ} \mathrm{C}\right)$. FITC, fluorescein isothiocyanate; PI, propidium iodide. 


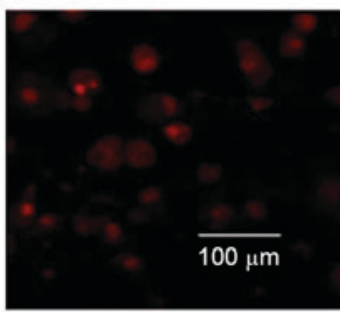

Control

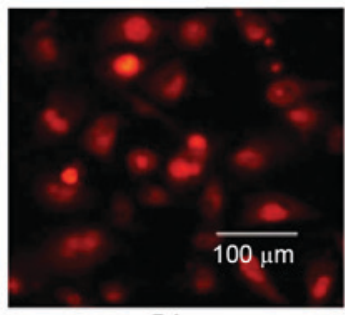

R6

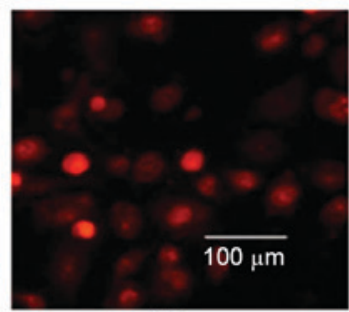

R0

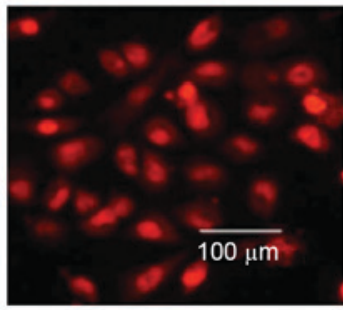

R12

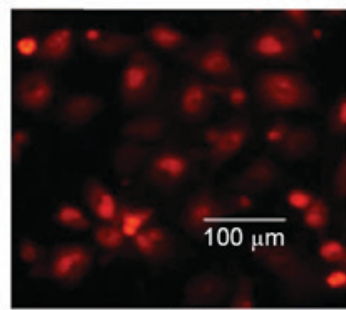

R3

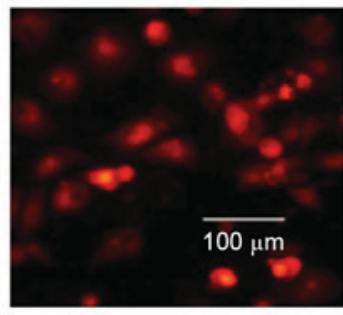

$\mathrm{H}_{2} \mathrm{O}_{2}$

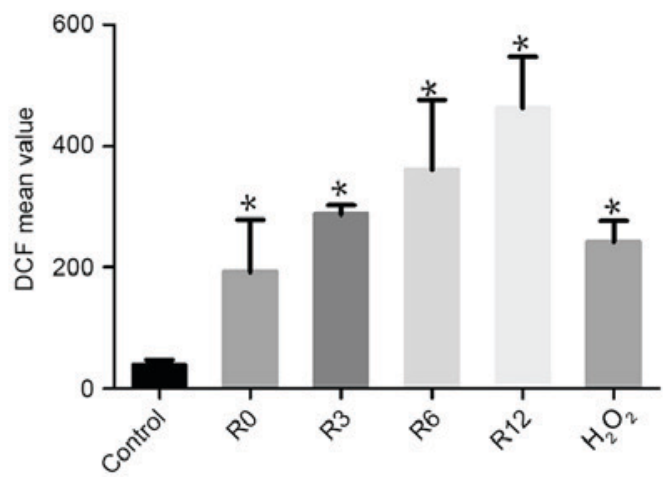

Figure 2. The influence of heat stress on ROS production in $\mathrm{F} 98$ cells. Cells underwent treatment for 60 min in a water bath at $43^{\circ} \mathrm{C}$ (heat stress) or $37^{\circ} \mathrm{C}$ (control), and then incubated at $37^{\circ} \mathrm{C}$ for the $0-12 \mathrm{~h}$ (R0 to R12, respectively). Assays of ROS quantity were performed using $2^{\prime}, 7^{\prime}$-dichlorodihydrofluorescein diacetate staining; images were obtained via laser scanning confocal microscopy, and analysis of the fluorescence intensity of ROS probes was performed using flow cytometry. *P<0.05 vs. control group. ROS, reactive oxygen species; DCF, 2',7'-dichlorofluorescein.

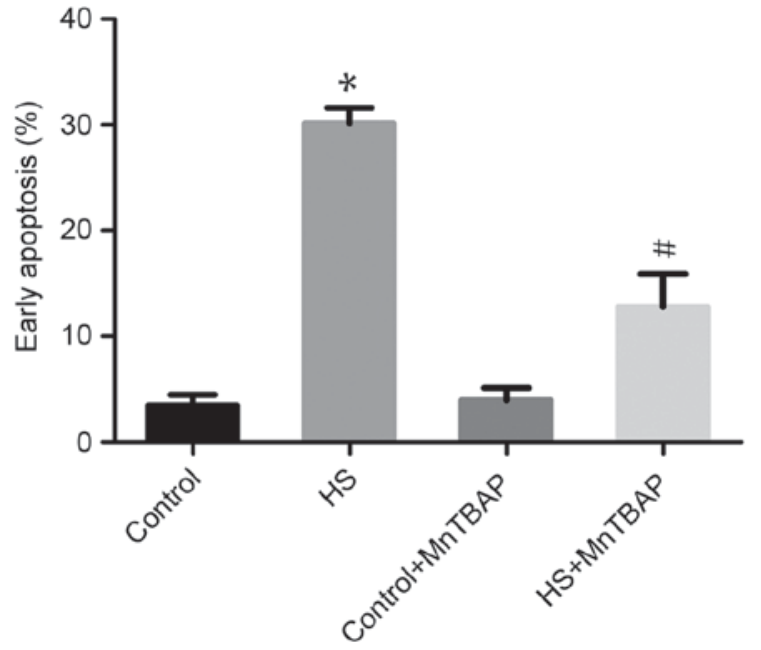

Figure 3. Reactive oxygen species are implicated in heat stress-induced glial cell apoptosis. F98 cells underwent a 1-h pretreatment with or without $\operatorname{MnTBAP}(10 \mu \mathrm{mol} / \mathrm{l})$ and were then subjected to incubation at $43^{\circ} \mathrm{C}$ (HS) or $37^{\circ} \mathrm{C}$ (control) for $60 \mathrm{~min}$ before further incubation for $12 \mathrm{~h}$ at $37^{\circ} \mathrm{C}$. Flow cytometry using Annexin V-fluorescein isothiocyanate/propidium iodide staining was performed to analyze apoptosis. " $\mathrm{P}<0.05$ vs. HS group, ${ }^{*} \mathrm{P}<0.05$ vs. control group. HS, heat stress.

Cells were subjected to heat stress at $43^{\circ} \mathrm{C}$ for $60 \mathrm{~min}$. Culture medium was substituted for fresh medium and the cells received further incubation at $37^{\circ} \mathrm{C}$ for $0,3,6$ or $12 \mathrm{~h}$. The levels of intracellular ROS increased in a time-dependent manner: $192.9 \pm 49.83$ at $0 \mathrm{~h}, 287.7 \pm 8.718$ at $3 \mathrm{~h}, 361.0 \pm 66.16$ at $6 \mathrm{~h}$ and $463.6 \pm 48.52$ at $12 \mathrm{~h}$, compared with the control treatment group $(38.44 \pm 4.83)$ respectively at $0,3,6$ and $12 \mathrm{~h}$, as demonstrated by flow cytometric analysis of DCF fluorescence. $\mathrm{H}_{2} \mathrm{O}_{2}$ was used as a positive control (Fig. 2).

Function of ROS in heat-stress-treated F98 cells. The role of ROS overproduction in heat-stress-induced apoptosis was investigated using the antioxidant MnTBAP to pretreat cells.

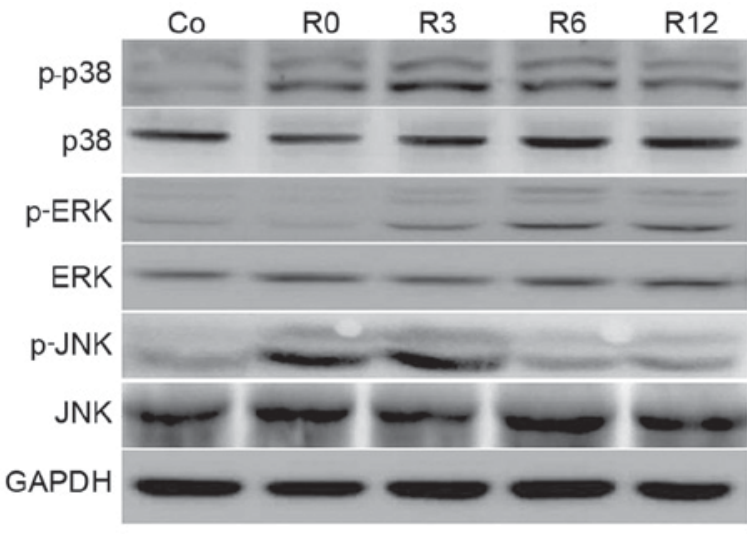

Figure 4. Mitogen-activated protein kinase activation by heat stress in neurons. F98 cells were submitted to heat stress treatment at $43^{\circ} \mathrm{C}$ for $60 \mathrm{~min}$ or control treatment $\left(37^{\circ} \mathrm{C}\right)$. Culture medium was then replaced and the cells were incubated at $37^{\circ} \mathrm{C}$ for $0,3,6,12 \mathrm{~h}$ ( $\mathrm{R} 0$ to R12, respectively). Antibodies for the indicated proteins were used assess the specific protein levels in the lysates. Co, control; p-, phosphorylated; ERK, extracellular signal-regulated kinase; JNK, c-Jun N-terminal kinase.

As the cell-permeable ROS scavenger MnTBAP depleted ROS, the proportion of F98 cells heat stress-induced early apoptosis was significantly reduced compared with heat-stressed cells not treated with MnTBAP ( $\mathrm{P}<0.05$; Fig. 3$)$. These data indicate that the apoptosis of neurons induced by heat stress is mediated by ROS release.

Heat stress induces MAPK activation in neurons. Activation of MAPK is implicated in enhanced cellular sensitivity to oxidative-stress-induced neuronal apoptosis (9). Therefore, the time course of MAPK phosphorylation in F98 cells stimulated by heat stress was investigated. The phosphorylation of p38 MAPK was rapid, peaking at $3 \mathrm{~h}$ and sustaining to $12 \mathrm{~h}$. Phosphorylation of JNK sustained to $3 \mathrm{~h}$ and declined following shock recovery. In contrast to p38 and JNK, ERK activation increased more gradually and peaked (Fig. 4). 
A

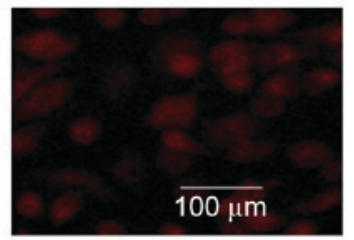

Control

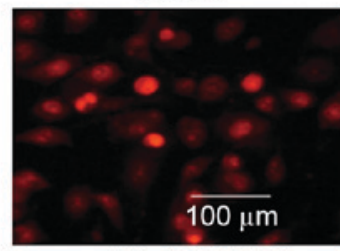

HS+SB203580

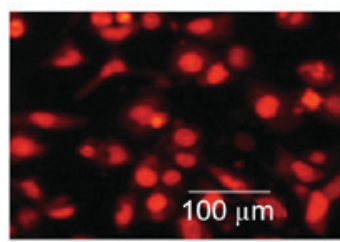

HS+SB202474

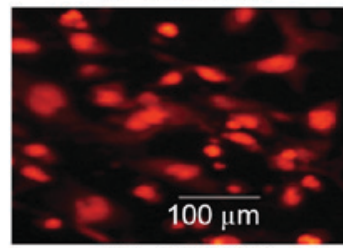

HS+PD98059

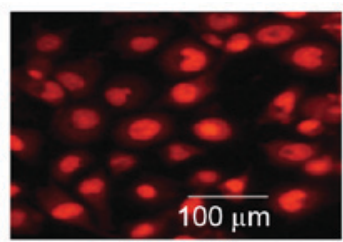

HS+SP600125

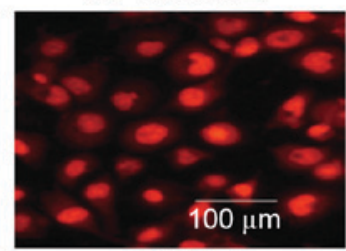

$\mathrm{H}_{2} \mathrm{O}_{2}$
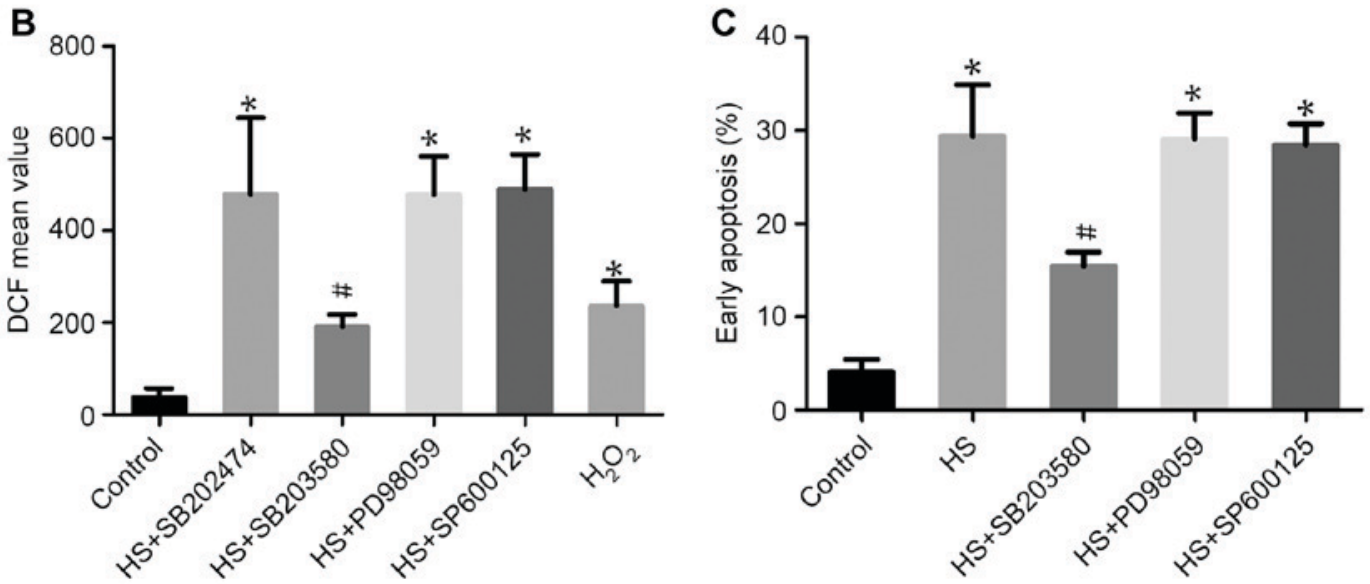

Figure 5. The role of mitogen-activated protein kinases in heat-stress-triggered apoptosis in neurons. F98 cells were pretreated with or without the indicated inhibitors prior exposure to heat stress or control heat treatment, and cells were further incubated for $12 \mathrm{~h}$ at $37^{\circ} \mathrm{C}$. $\mathrm{H}_{2} \mathrm{O}_{2}$ was used as a positive control for ROS (A and B) ROS quantity was assessed by 2',7'-dichlorodihydrofluorescein diacetate staining; (A) images were obtained via laser scanning confocal microscopy and (B) analysis of the fluorescence intensity of ROS probes was performed using flow cytometry. (C) Analysis of apoptosis was performed through flow cytometry using Annexin V-fluorescein isothiocyanate/propidium iodide staining. ${ }^{*} \mathrm{P}<0.05$ vs. HS group, ${ }^{*} \mathrm{P}<0.05$ vs. control group. ROS, reactive oxygen species; HS, heat stress; SB203580, p38 inhibitor; SP600125, JNK inhibitor; PD98059, ERK inhibitor; DCF, 2',7'-dichlorofluorescein.

p38 activation is involved in heat-stress-induced apoptosis. To examine the function of MAPK activation in heat-stress-induced apoptosis, F98 cells underwent heat stress with or without MAPK inhibitors. As shown in Fig. 5, incubation with SB203580 (a p38-specific inhibitor) alone substantially decreased ROS production and the number of cells in early apoptosis. Incubation with PD98059 (an ERK-specific inhibitor) and SP600125 (a JNK-specific inhibitor) exerted no effect on ROS production or cell apoptosis compared with the heat-shock group that did not receive additional treatment.

SB203580 inhibits heat stress-induced MK2 and MK5 activation. To investigate whether MAPKs have an effect on downstream MK2 and MK5 in heat-stressed F98 cells, MAPK inhibitors were used pretreat cells, with SB202474 used as a control. SB203580 (the specific inhibitor of p38) suppressed the heat-stress-induced activation of MK5 and MK2, whereas PD98059 (the inhibitor of ERK) and SP600125 (the inhibitor of JNK) exerted no such effect (Fig. 6). These results indicate that MK2 and MK5 activation occurs downstream of p38 activation.

Activation of MK2 induces neuronal ROS productionmediated apoptosis. To investigate whether MK2 and MK5

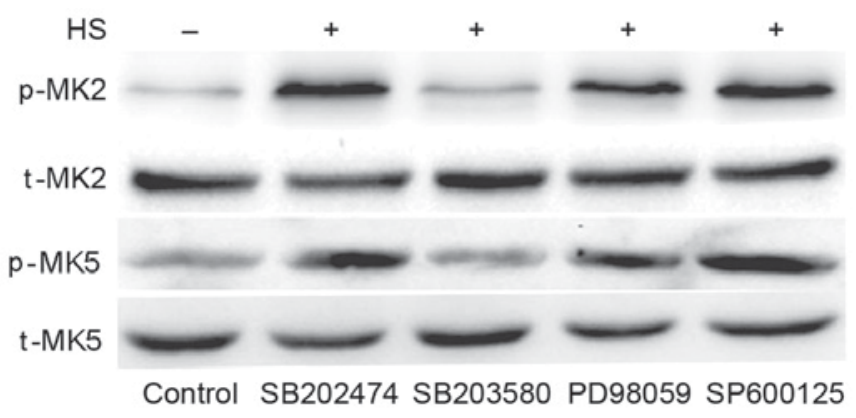

Figure 6. Inhibition of p38 weakens heat stress-induced phosphorylation of MK5 and MK2. F98 cells underwent pretreatment with or without the indicated inhibitors for $30 \mathrm{~min}$ prior to exposure to heat stress or control heat treatment. After the cells received further incubation for $12 \mathrm{~h}$ at $37^{\circ} \mathrm{C}$, antibodies specific for p-MK2, p-MK5, MK2, MK5 were used to assess the protein levels in the cell lysates. HS, heat stress; p-, phosphorylated; t-, total; MK, mitogen-activated protein kinase-activated protein kinase; SB203580, p38 inhibitor; PD98059, ERK inhibitor; SP600125, JNK inhibitor.

have an effect on p38 MAPK-mediated ROS production and cell apoptosis, F98 cells were transfected with an adenoviral dominant-active form of p38 or a dominant-negative MK2 and MK5. ROS production and cell apoptosis were induced by transfection with Ad-MKK6b(E), the dominant active 
A

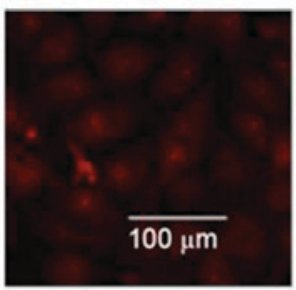

Control

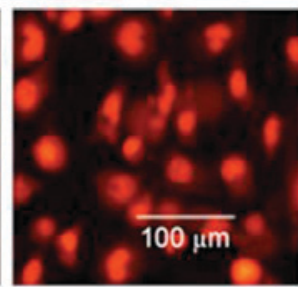

AdMKK6b (E)

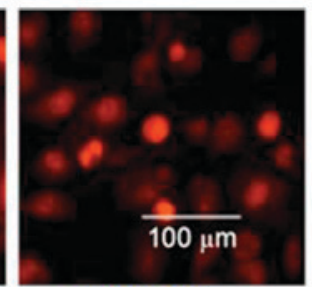

AdMKK6b (E) +AdMK2 (A)

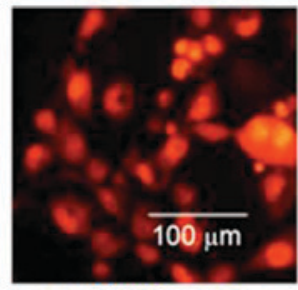

AdMKK6b (E) +AdMK5 (A)

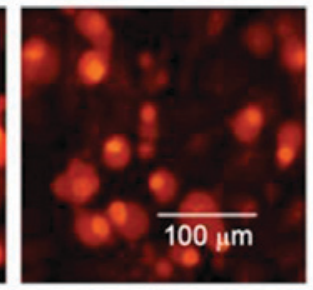

$\mathrm{H}_{2} \mathrm{O}_{2}$
B

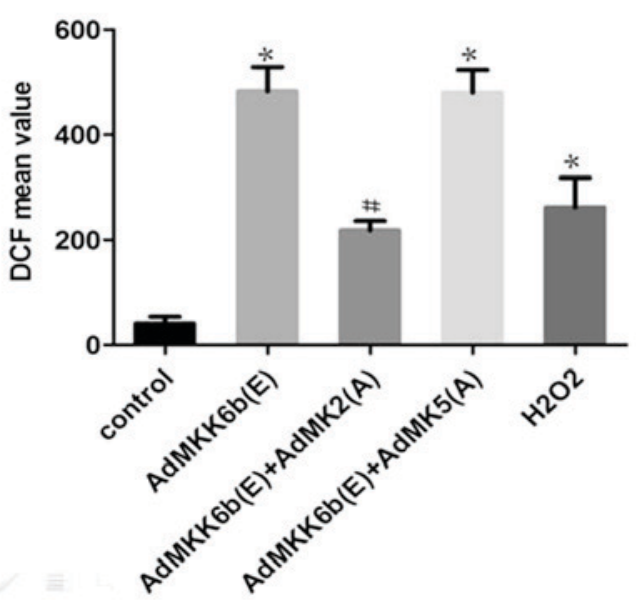

C

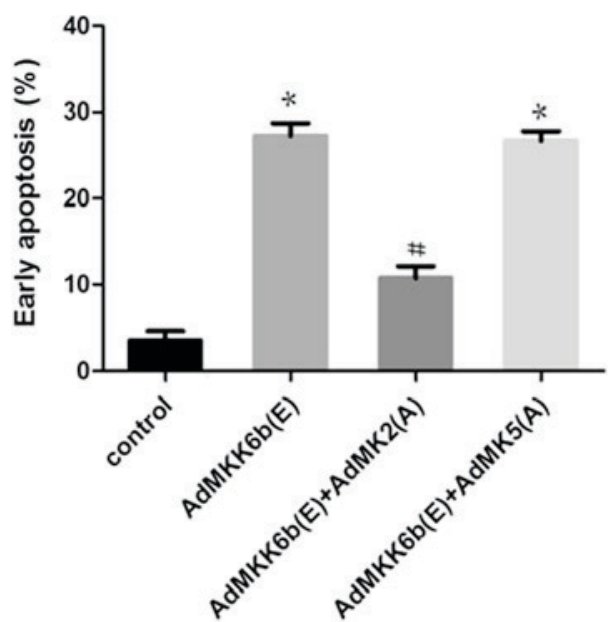

Figure 7. Activation of MK2 induces ROS production mediating glial cell apoptosis. The dominant active form of recombinant adenoviral p38 or dominant negative MK2 and MK5 recombinant adenoviral were transfected into F98 cells before exposure to heat stress or control heat treatment, and the cells received further incubation for $12 \mathrm{~h}$ at $37^{\circ} \mathrm{C}$. (A and B) ROS quantity was assessed using 2',7'-dichlorodihydrofluorescein diacetate staining; (A) images were obtained via laser scanning confocal microscopy and (B) analysis of the fluorescence intensity of ROS probes was performed by flow cytometry. (C) Analysis of apoptosis was performed via flow cytometry utilizing Annexin V-fluorescein isothiocyanate/propidium iodide staining. ${ }^{\#} \mathrm{P}<0.05$ vs. HS group. ${ }^{*} \mathrm{P}<0.05$ vs. control group. ROS, reactive oxygen species; MK, mitogen-activated protein kinase-activated protein kinase; DCF, 2',7'-dichlorofluorescein; MKK6b, MAPK kinase $6 b$.

kinase MKK6b (upstream of p38), whose effect was strikingly weakened upon co-transfection with Ad-MK2(A), an adenoviral construct of the dominant negative MK2; however, co-transfection with dominant-negative MK5 [Ad-MK5(A)] to inhibit MK5 did not elicit a similar response (Fig. 7).

Inhibition of MK2 activation alleviates heat-stress-induced ROS production and glial cell apoptosis. Whether heat stress-induced ROS production and apoptosis could be suppressed by inhibition of MK2 or MK5 was assessed. As shown in Fig. 8A and B, the results revealed that incubation with CMPD-1 (a specific inhibitor of MK2) or transfection with Ad-MK2(A) inhibited heat stress-induced ROS accumulation, whereas transfection with Ad-MK5(A) exerted no such inhibitory function. $\mathrm{H}_{2} \mathrm{O}_{2}$ was used as a positive control. The effect of MK2 inhibition on cell apoptosis was further investigated. The results revealed that transfection with Ad-MK2(A) or incubation with CMPD-1 decreased heat-stress-induced cell apoptosis, while transfection with Ad-MK5(A) did not (Fig. 8C).

\section{Discussion}

The number of studies investigating the influence of heat stress continues to rise owing to fluctuations in temperature being among the most common stressors in biological systems $(5,21)$. In a previous study, following the selective heating of hemispheres of the canine brain above $42-43^{\circ} \mathrm{C}$ for $30 \mathrm{~min}$, several histopathological changes, including focal hemorrhages, spotty infarction and edema, were observed (22). Subsequent to heating at $43^{\circ} \mathrm{C}$ for $50 \mathrm{~min}$, impairments of myelin tracts in the white matter and neurons in the gray matter of the brains were immediately observed (22). A cerebral lesion composed of a central coagulation of necrosis encircled by a hypervascular section with clear contours was observed by Sneed et al (19) in 1986, when the canine brain was subjected to a 30-min single heat treatment at $43-44^{\circ} \mathrm{C}(19)$. Heat stress may be the cause of a reduction in the cellular processes initiated by various regional neurons in the CNS, and apoptosis may be integrally involved in the CNS injury of heat-involved diseases ascribed to heat stress (6).

The present study used the rat glioma F98 cell line to study the mechanism of CNS injury caused by heat stress. The results indicated that apoptosis was induced by heat stress in F98 cell lines. The expression of MAPKs in heat stressed F98 cells was assessed, and it was found that high-intensity heat stress triggered MAPK activation. p38 activation was implicated in heat stress-induced ROS accumulation-mediated apoptosis, but neither JNK nor ERK had any effect on this, which could 
A

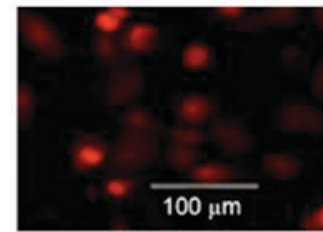

Control

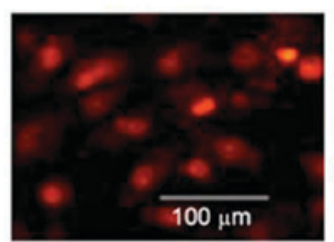

HS+AdMK2 (A)

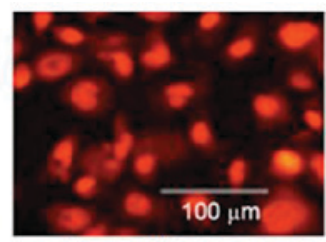

HS

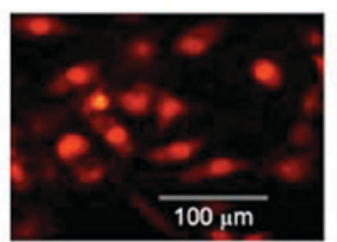

HS+AdMK5 (A)

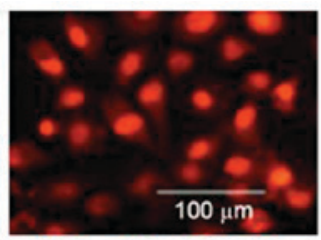

HS+AdMK5 (A)

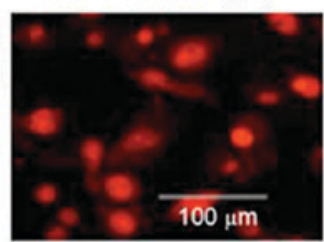

$\mathrm{H}_{2} \mathrm{O}_{2}$
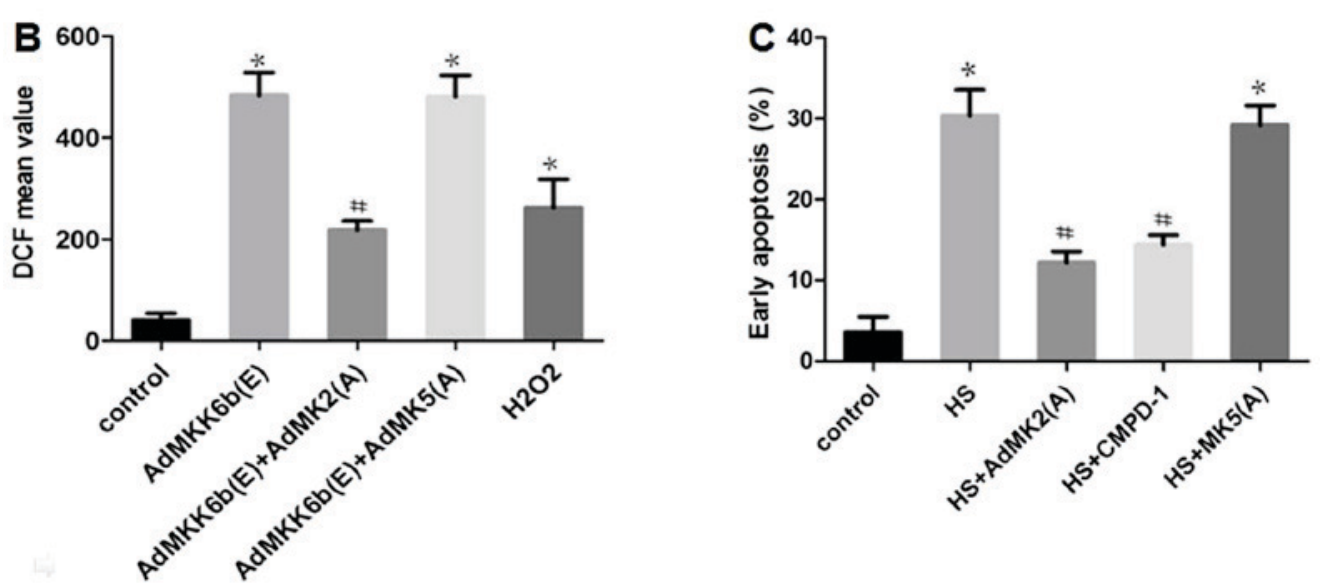

Figure 8. Inhibiting MK2, but not MK5, alleviates heat-stress-induced apoptosis. F98 cells were transfected with adenoviral dominant negative form of MK5 and MK2 prior to exposure to heat stress $\left(43^{\circ} \mathrm{C}, 1 \mathrm{~h}\right)$ or control treatment, and the cells were incubated for $12 \mathrm{~h}$ at $37^{\circ} \mathrm{C}$. (A and B) Assay of ROS quantity was performed using $2^{\prime}, 7^{\prime}$-dichlorodihydrofluorescein diacetate staining; (A) images were obtained via laser scanning confocal microscopy and (B) analysis of the fluorescence intensity of ROS probes was performed by flow cytometry. (C) Analysis of apoptosis was performed through flow cytometry using Annexin V-fluorescein isothiocyanate/propidium iodide staining. ${ }^{\#} \mathrm{P}<0.05$ vs. the HS group, ${ }^{*} \mathrm{P}<0.05$ vs. the control group. ROS, reactive oxygen species; MK, mitogen-activated protein kinase-activated protein kinase; HS, heat stress; CMPD-1, MK2 inhibitor; DCF, 2',7'-dichlorofluorescein.

implicate ROS associated with intense heat stress. Our and previous reports have associated oxidative stress with heat stress and suggested synergistic augmentation of cell death and increased ROS generation in heat-exposed cells (17,23-25). The present study indicated that mediation of oxidative stress is mainly achieved by intense heat stress, inducing an increase in ROS production. Using the cell-permeable ROS scavenger MnTBAP, it was further found that heat stress generates ROS. Taken together, the results suggest that the proportion of F98 cells exposed to heat stress in early apoptosis is increased by ROS accumulation, whereas $\mathrm{p} 38$, a product of acute heat stress, may function as an upstream signal that stimulates this accumulation.

Inhibition of different MAPKs with specific inhibitors indicated that the p38 inhibitor (SB203580), but not the JNK inhibitor (SP600125) or ERK inhibitor (PD98059) could suppress activation of the p38 downstream kinases MK2 and MK5 in neurons. Inhibiting MK2 by transfection with Ad-MK2(A) or incubation with its specific inhibitor markedly decreased normal and heat stress-induced ROS accumulation and cell apoptosis, whereas inhibition of another downstream p38 MAPK kinase, MK5, by transfection with Ad-MK5(A), did not exert the same effects.

The p38 MAPK-MK2 family has been demonstrated to modulate apoptosis in response to various stimuli $(26,27)$, including in neurons (16). A previous study reported that the apoptosis induced by doxorubicin in human hepatoma cells, alongside the cleavage of caspase- 3 and poly(ADP-ribose) polymerase, can be diminished by the constant overexpression of MK5, which is also referred to as p38-regulated/activated protein kinase or PRAK (28). In the present study, MK5 was recognized as a downstream target of p38 MAPK in heat-stressed F98 cells, but exerted no effect on cell apoptosis. On the basis of these results, it was concluded that heat stress stimulation induced p38-MK2 pathways activation, which served a pro-apoptotic role by regulating ROS accumulation in glial cells.

To conclude, the data obtained in the present study revealed that heat stress rapidly leads to apoptosis of F98 cells. Early apoptosis induced by intense heat stress is associated with p38MAPK-MK2 signaling, which is in turn mediated by ROS generation. The present study provides novel strategies for treatment of heat-associated CNS injury in which glial cell apoptosis occurs.

\section{Acknowledgements}

The present study was supported by the project team of Natural Science Foundation of Guangdong Province (grant no. 2013030013217) 


\section{References}

1. Malamud N, Haymaker W and Custer RP: Heat stroke: A clinicoorgan pathological study of 125 fatal cases. Mil Surg 99: 394-449, 1946

2. Hausfater P, Megarbane B, Dautheville S, Patzak A Andronikof M, Santin A, André S, Korchia L, Terbaoui N, Kierzek G, et al: Prognostic factors in non-exertional heatstroke. Intensive Care Med 36: 272-280, 2010.

3. Dematte JE, O'Mara K, Buescher J, Whitney CG, Forsythe S, McNamee T, Adiga RB and Ndukwu IM: Near-fatal heat stroke during the 1995 heat wave in Chicago. Ann Intern Med 129: 173-181, 1998.

4. Mastrangelo G, Fedeli U, Visentin C, Milan G, Fadda E and Spolaore P: Pattern and determinants of hospitalization during heat waves: An ecologic study. BMC Public Health 7: 200, 2007.

5. Kovats RS and Kristie LE: Heatwaves and public health in Europe. Eur J Public Health 16: 592-599, 2006.

6. Edwards MJ, Walsh DA and Li Z: Hyperthermia, teratogenesis and the heat shock response in mammalian embryos in culture Int J Dev Biol 41: 345-358, 1997.

7. Yu J, Liu F, Yin P, Zhao H, Luan W, Hou X, Zhong Y, Jia D, Zan J, Ma W, et al: Involvement of oxidative stress and mitogen-activated protein kinase signaling pathways in heat stress-induced injury in the rat small intestine. Stress 16: 99-113, 2013.

8. Liu Y,Zhou G, Wang Z, Guo X, Xu Q, Huang Q and Su L: NF-кB signaling is essential for resistance to heat stress-induced early stage apoptosis in human umbilical vein endothelial cells. Sci Rep 5: 13547, 2015.

9. Chang L and Karin M: Mammalian MAP kinase signalling cascades. Nature 410: 37-40, 2001.

10. Seger R and Krebs EG: The MAPK signaling cascade. FASEB J 9: 726-735, 1995

11. Roux PP and Blenis J: ERK and p38 MAPK-activated protein kinases: A family of protein kinases with diverse biological functions. Microbiol Mol Biol Rev 68: 320-344, 2004.

12. Kim EK and Choi EJ: Pathological roles of MAPK signaling pathways in human diseases. Biochim Biophys Acta 1802: 396-405, 2010

13. Cargnello M and Roux PP: Activation and function of the MAPKs and their substrates, the MAPK-activated protein kinases. Microbiol Mol Biol Rev 75: 50-83, 2011.

14. Gaestel M: MAPKAP kinases-MKs-two's company, three's a crowd. Nat Rev Mol Cell Biol 7: 120-30, 2006.

15. New L, Jiang Y, Zhao M, Liu K, Zhu W, Flood LJ, Kato Y, Parry GC and Han J: PRAK, a novel protein kinase regulated by the p38 MAP kinase. EMBO J 17: 3372-3384, 1998.
16. Liu R, Wu CX, Zhou D, Yang F, Tian S, Zhang L, Zhang TT and Du GH: Pinocembrin protects against $\beta$-amyloid-induced toxicity in neurons through inhibiting receptor for advanced glycation end products (RAGE)-independent signaling pathways and regulating mitochondrion-mediated apoptosis. BMC Med 10: 105, 2012.

17. Gu ZT, Wang H, Li L, Liu YS, Deng XB, Huo SF, Yuan FF, Liu ZF, Tong HS and Su L: Heat stress induces apoptosis through transcription-independent p53-mediated mitochondrial pathways in human umbilical vein endothelial cell. Sci Rep 4: 4469,2014

18. Fiers W, Beyaert R, Declercq W and Vandenabeele P: More than one way to die: Apoptosis, necrosis and reactive oxygen damage. Oncogene 18: 7719-7730, 1999.

19. Sneed PK, Matsumato K, Stauffer PR, Fike JR, Smith V and Gutin PH: Interstitial microwave hyperthermia in a canine brain model. Int J Radiat Oncol Biol Phys 12: 1887-1897, 1986.

20. Wu W, Huan Q, Miao J, Xiao M, Liu H, Zhao K and Zhao M: MK2 plays an important role for the increased vascular permeability that follows thermal injury. Burns 39: 923-934, 2013.

21. Dorozynski A: Chirac announces investigation into heat wave's death toll. BMJ 327: 465, 2003.

22. Harris AB, Erickson L, Kendig JH, Mingrino S and Goldring S: Observations on selective brain heating in dogs. J Neurosurg 19 514-521, 1962.

23. Burdon RH, Gill VM and Rice-Evans C: Oxidative stress and heat shock protein induction in human cells. Free Radic Res Commun 3: 129-139, 1987.

24. Skibba JL, Powers RH, Stadnicka A, Cullinane DW, Almagro UA and Kalbfleisch JH: Oxidative stress as a precursor to the irreversible hepatocellular injury caused by hyperthermia. Int J yperthermia 7: 749-761, 1991.

25. McAnulty SR, McAnulty L, Pascoe DD, Gropper SS, Keith RE, Morrow JD and Gladden LB: Hyperthermia increases exercise-induced oxidative stress. Int J Sports Med 26: 188-192, 2005.

26. Cuenda A and Rousseau S: p38 MAP-kinases pathway regulation, function and role in human diseases. Biochim Biophys Acta 1773: 1358-1375, 2007.

27. Cuadrado A and Nebreda AR: Mechanisms and functions of $\mathrm{p} 38$ MAPK signaling. Biochem J 429: 403-417, 2010.

28. Zhou J, Wan B, Liu XM, Li R, Wang Y and Yu L: MK5 is degraded in response to doxorubicin and negatively regulates doxorubicin-induced apoptosis in hepatocellular carcinoma cells. Biochem Biophys Res Commun 427: 581-586, 2012. This work is licensed under a Creative Commons Attribution-NonCommercial-NoDeriva International (CC BY-NC-ND 4.0) License. 